Article

\title{
Steady-State Creep of Asphalt Concrete
}

\author{
Alibai Iskakbayev ${ }^{1}$, Bagdat Teltayev ${ }^{2, *}$ and Cesare Oliviero Rossi ${ }^{3}$ \\ 1 Department of Mechanics, Al-Farabi Kazakh National University, Almaty 050040, Kazakhstan; \\ iskakbayeva@inbox.ru \\ 2 Kazakhstan Highway Research Institute, Almaty 050061, Kazakhstan \\ 3 Department of Chemistry and Chemical Technologies, University of Calabria, Rende 87036, Italy; \\ cesare.oliviero@unical.it \\ * Correspondence: bagdatbt@yahoo.com; Tel.: +7-701-760-6701 \\ Academic Editors: Zhanping You, Qingli (Barbara) Dai and Feipeng Xiao \\ Received: 11 November 2016; Accepted: 25 January 2017; Published: 4 February 2017
}

\begin{abstract}
This paper reports the experimental investigation of the steady-state creep process for fine-grained asphalt concrete at a temperature of $20 \pm 2{ }^{\circ} \mathrm{C}$ and under stress from 0.055 to $0.311 \mathrm{MPa}$ under direct tension and was found to occur at a constant rate. The experimental results also determined the start, the end point, and the duration of the steady-state creep process. The dependence of these factors, in addition to the steady-state creep rate and viscosity of the asphalt concrete on stress is satisfactorily described by a power function. Furthermore, it showed that stress has a great impact on the specific characteristics of asphalt concrete: stress variation by one order causes their variation by 3-4.5 orders. The described relations are formulated for the steady-state of asphalt concrete in a complex stressed condition. The dependence is determined between stress intensity and strain rate intensity.
\end{abstract}

Keywords: asphalt concrete; creep curve; steady-state creep; strain rate; viscosity; stress intensity; strain intensity

\section{Introduction}

Asphalt concrete is one of the main materials used for highway pavements. Mechanical properties of an asphalt concrete are highly dependent on temperature and time of loading [1-3]. Therefore, the determination of the mechanical behavior of an asphalt concrete, taking into account the variation of the above-mentioned factors, has important practical value.

It is known that the basic methods for evaluating the mechanical behavior of viscoelastic materials are tests on creep and relaxation [4-6]. Technically, creep test investigations are easy to conduct, and their results make it possible to construct creep and long-term strength curves. Relaxation curves can be obtained from the creep curves by using known methods [6,7]. The long-term strength curves enable us to determine the service life of an asphalt concrete pavement.

The work in Reference [8] analyzes experimentally the process of uniaxial and triaxial creep for two asphalt concrete types (dense bitumen macadam and hot rolled asphalt) at a temperature range of 10 to $40{ }^{\circ} \mathrm{C}$. It was determined that the creep curve of asphalt concretes has three characteristic stages, the second of which (steady-state creep stage) has a constant strain rate. The viscosity of asphalt concretes for this stage of creep curve depends nonlinearly on the stress.

As the result of experimental tests for four asphalt concrete types, Hassan [9] approximated the first and the second stages of the creep curve by power function. However, an attempt to establish a linear correlation relationship between an exponent of power function and an exponent of Paris law was not successful.

Soleimanbeigi et al. [10] obtained results experimentally that demonstrated the creep strain rate of recycled asphalt shingles with bottom ash (RAS-BA) increased the most with the increase of applied 
stress value. The relationship of creep strain rate with stress is described by the power function and showed that the strain and the strain rate of creep increased with a temperature increase.

The asphalt concrete test for uniaxial creep at four different temperatures and three levels of stress, with the purpose of permanent strain evaluation was performed by Mahan [11]. Test results showed that both stress and temperature impact greatly on creep strain and permanent strain. Having tested the cylindrical specimens of two asphalt concrete types for uniaxial creep during compression at the temperatures of 25,40 , and $60{ }^{\circ} \mathrm{C}$ and three levels of stress, Zhigang et al. [12] also determined that the creep curve of asphalt concrete had three stages, where the second stage had a constant strain rate. The authors defined creep strain as a viscous flow deformation, and also called the gradual reduction of deformation on the first stage and maintenance of strain rate as a constant on the second stage as the "consolidation effect". Either temperature or stress greatly impacts creep strain. The greater the temperature, the less the asphalt concrete resists strain. The greater the stress at a similar temperature, the faster the damage occurs. The time period for the test was $5000 \mathrm{~s}$. A simple model of creep with five parameters was determined from a generalized model of Kelvin, and was proposed for the same maximum duration of deformation.

The work in Reference [13] used the test results of asphalt concretes based on the three point bending test at different temperatures and levels of stress to develop master curves of stiffness modulus.

In this paper, test results of hot fine-grained asphalt concrete samples on creep are presented. Creep tests were carried out by a direct tensile scheme until complete fracture of the asphalt concrete samples was obtained. The test temperature was $20 \pm 2{ }^{\circ} \mathrm{C}$. The applied stress was changed from 0.055 to $0.311 \mathrm{MPa}$. Creep curves under different loads of the asphalt concrete were constructed. Three characteristic stages of creep curves-the unsteady-state, the steady-state, and the accelerating creep stages-are shown. The first creep curve stage of asphalt concrete was satisfactorily approximated by Rabotnov's fractional exponential function [14]. A description of the third creep curve stage should be carried out on the basis of continuum damage mechanics approach $[15,16]$, which is currently work in progress. Therefore, the second stage of the asphalt concrete creep curve is described.

\section{Materials and Methods}

\subsection{Bitumen}

Bitumen of grade 100-130, which met the requirements of the Kazakhstan standard [17], was used in this study. The bitumen grade on Superpave is PG (Performance Grade) 64-40 [18]. Basic standard indicators of the bitumen are shown in Table 1. Bitumen is produced by the Pavlodar processing plant from the crude oil of Western Siberia (Oil processing plant, Omsk, Russia) by the direct oxidation method.

Table 1. Basic standard indicators of the bitumen, ST RK: Standard of the Republic of Kazakhstan.

\begin{tabular}{lccc}
\hline Indicator & Measurement Unit & Requirements of ST RK 1373 & Value \\
\hline Penetration, $25{ }^{\circ} \mathrm{C}, 100 \mathrm{gr}, 5 \mathrm{~s}$ & $0.1 \mathrm{~mm}$ & $101-130$ & 104 \\
Penetration Index PI & - & $-1.0, \ldots,+1.0$ & -0.34 \\
Tensility at temperature: & $\mathrm{cm}$ & - & - \\
$25^{\circ} \mathrm{C}$ & - & $\geq 90$ & 140 \\
$0^{\circ} \mathrm{C}$ & - & $\geq 4.0$ & 5.7 \\
Softening point & ${ }^{\circ} \mathrm{C}$ & $\geq 43$ & 46.0 \\
Fraas point & ${ }^{\circ} \mathrm{C}$ & $\geq 120$ & -25.9 \\
Dynamic viscosity, $60^{\circ} \mathrm{C}$ & $\mathrm{Pa} \cdot \mathrm{s}$ & $\geq 180$ & 175.0 \\
Kinematic viscosity & $\mathrm{mm}^{2} / \mathrm{s}$ & 398.0 \\
\hline
\end{tabular}

\subsection{Asphalt Concrete}

Hot dense asphalt concrete of type B that met the requirements of the Kazakhstan standard [19] was prepared with the use of aggregate fractions of 5-10 mm (20\%); 10-15 mm (13\%); and 15-20 mm 
(10\%) from the Novo-Alekseevsk rock pit (Almaty region, Kazakhstan); sand of fraction 0-5 mm (50\%) from the plant "Asphaltconcrete-1" (Almaty city, Kazakhstan); and activated mineral powder (7\%) from the Kordai rock pit (Zhambyl region, Kazakhstan).

The bitumen content of grade 100-130 in the asphalt concrete was $4.8 \%$ by weight of dry mineral material. Basic standard indicators of the aggregate and the asphalt concrete are shown in Tables 2 and 3, respectively. A granulometric composition curve for the mineral part of asphalt concrete is shown in Figure 1.

Table 2. Basic standard indicators of the crushed stone.

\begin{tabular}{ccccc}
\hline Indicator & $\begin{array}{c}\text { Measurement } \\
\text { Unit }\end{array}$ & $\begin{array}{c}\text { Requirements of } \\
\text { ST RK 1284 [20] }\end{array}$ & Fraction 5-10 mm & Fraction 10-20 mm \\
\hline Average density & $\mathrm{g} / \mathrm{cm}^{3}$ & - & 2.55 & 2.62 \\
Elongated particle content & $\%$ & $\leq 25$ & 13 & 9 \\
Clay particle content & $\%$ & $\leq 1.0$ & 0.3 & 0.2 \\
Bitumen adhesion & - & - & satisf. & satisf. \\
Water absorption & $\%$ & - & 1.93 & 0.90 \\
\hline
\end{tabular}

Table 3. Basic standard indicators of the asphalt concrete.

\begin{tabular}{cccc}
\hline Indicator & Measurement Unit & Requirements of ST RK 1225 & Value \\
\hline Average density & $\mathrm{g} / \mathrm{cm}^{3}$ & - & 2.39 \\
Water saturation & $\%$ & $1.5-4.0$ & 2.3 \\
Voids in mineral aggregate & $\%$ & $\leq 19$ & 14 \\
Air void content in asphalt concrete & $\%$ & $2.5-5.0$ & 3.8 \\
Compression strength at temperature & $\mathrm{MPa}$ & - & - \\
$0^{\circ} \mathrm{C}$ & - & $\leq 13.0$ & 7.0 \\
$20^{\circ} \mathrm{C}$ & - & - & 3.4 \\
$50^{\circ} \mathrm{C}$ & - & $\geq 1.3$ & 1.4 \\
\hline
\end{tabular}

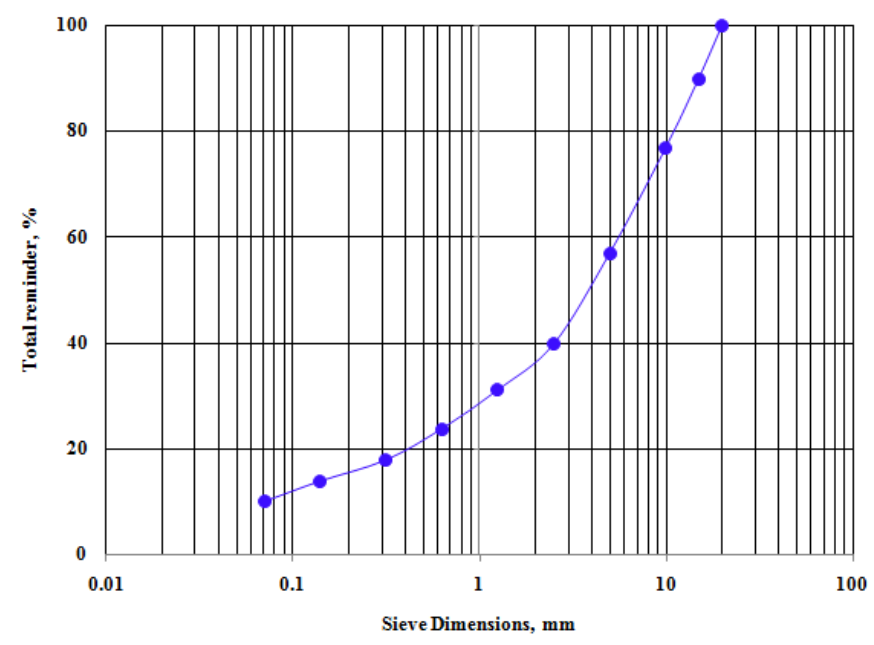

Figure 1. Granulometric curve of mineral part of the asphalt concrete.

\subsection{Sample Preparation}

Samples of the hot asphalt concrete in the form of a rectangular prism with dimensions $15,050 \times 50 \mathrm{~mm}$ (Figure 2) were manufactured as follows. First, the asphalt concrete samples were prepared in the form of a square slab (Figure 3) using a Cooper compactor (model CRT-RC2S, Cooper, Nottingham, UK) (Figure 4) according to the standard in [21]. The samples were then cut from the asphalt concrete slabs in the form of a prism. Deviations in sizes of the beams did not exceed two millimeters. 


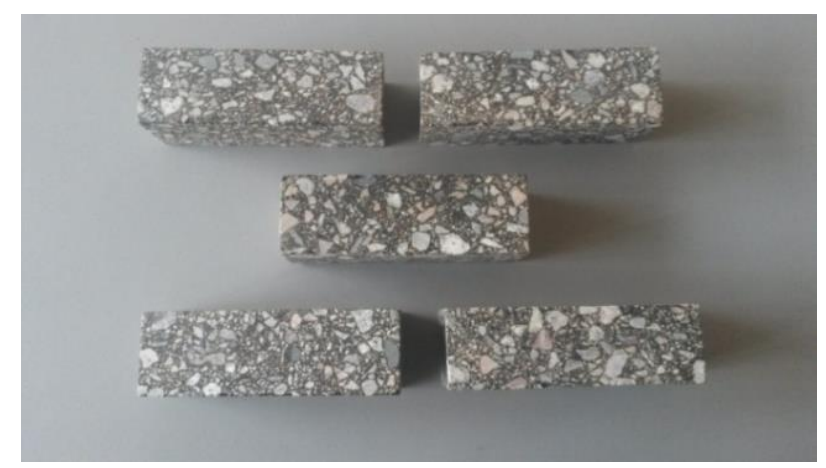

Figure 2. Samples of the asphalt concrete with dimension $150 \times 50 \times 50 \mathrm{~mm}$.

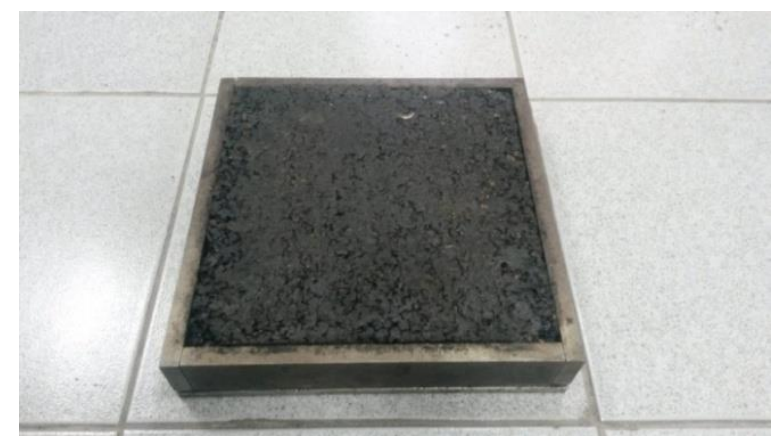

Figure 3. A square slab with dimension $305 \times 305 \times 50 \mathrm{~mm}$.

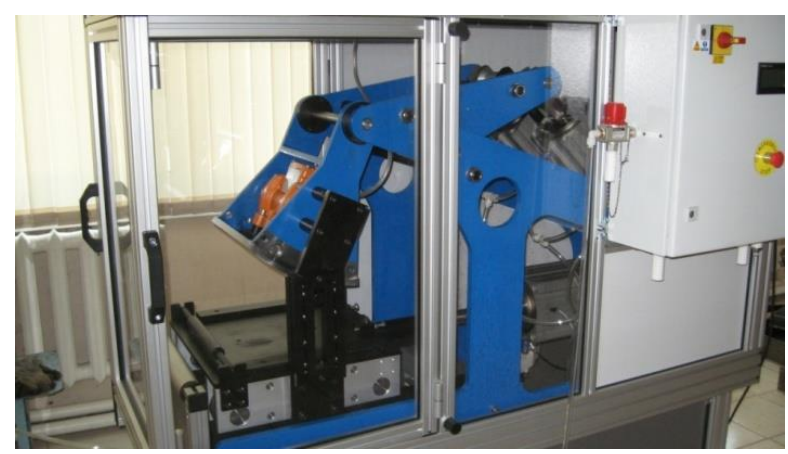

Figure 4. The Cooper compactor CRT-RC2S.

\subsection{Test}

Tests on creep were carried out on hot asphalt concrete samples in the form of a rectangular prism, according to the direct tensile scheme until complete failure was reached. The test temperature was equal to $20 \pm 2{ }^{\circ} \mathrm{C}$, stress was variable from 0.055 to $0.311 \mathrm{MPa}$. The tests were carried out in a specially assembled installation (Figure 5). The sample strain was measured by means of two clock type indicators while data were recorded on a video camera. 


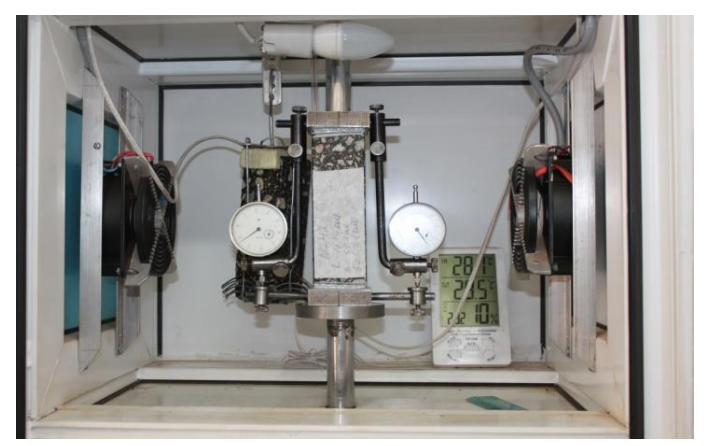

Figure 5. A specially assembled installation for creep test.

\section{Results and Discussion}

\subsection{Creep Curve}

Previous works $[14,22,23]$ showed that an asphalt concrete creep curve-as with most viscoelastic materials-had three characteristic stages: stage I of unsteady-state creep with decreasing rate; stage II of steady-state creep with a constant (minimum) rate; and stage III of accelerating creep with increasing rate which precedes failure. The above studies presented test results of asphalt concrete for creep with relatively narrow ranges of stress variation. This work includes test results for seven values of stress from 0.055 MPa to $0.311 \mathrm{MPa}$. Practically, five samples of asphalt concrete were tested for each value of stress.

Figure 6 shows the creep curve for asphalt concrete at stress $0.117 \mathrm{MPa}$. It is clearly seen that the creep curve contains all three stages. It is important to underline that since the beginning of loading to the failure moment, the asphalt concrete passes three stages of deformation.

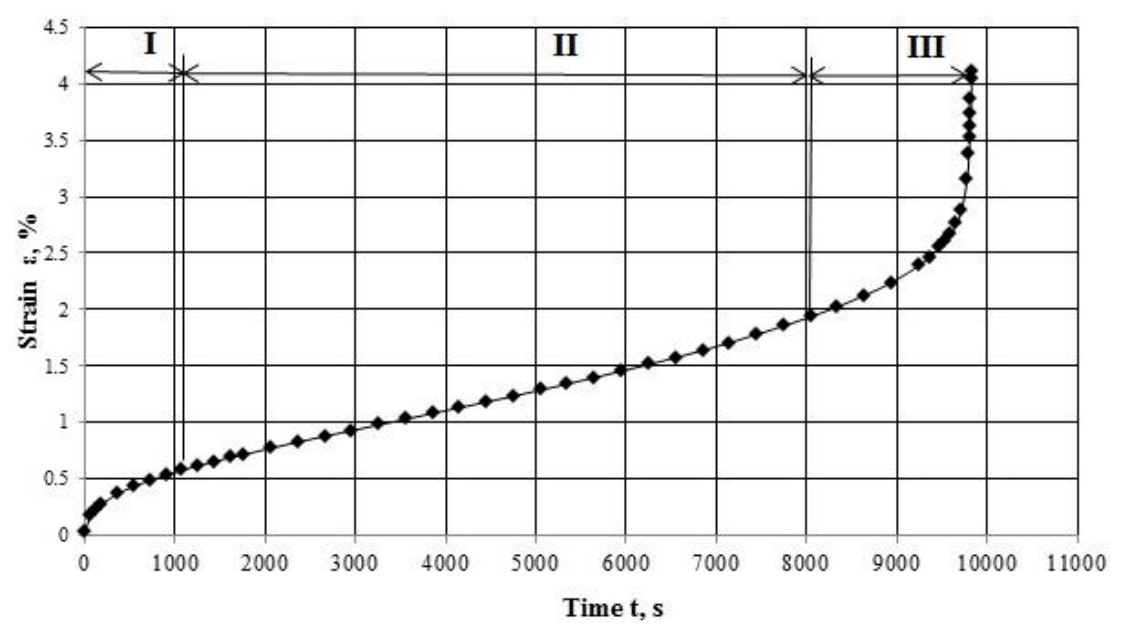

Figure 6. The asphalt concrete creep curve at stress $0.117 \mathrm{MPa}$.

\subsection{Steady-State Creep}

To solve practical problems, it is important to describe a creep curve obtained experimentally. Usually the third stage of the creep curve for the material is not considered in engineering calculations, as within its range the intensive accumulation of damage occurs, which results in a short life [16]. Therefore, the first and second stages of the creep curve are of main interest for mathematical description. The first stage of the creep curve for asphalt concrete was described with the use of Rabotnov's fractional exponential function [16] and was reported previously by the authors of Reference [14]. 
Analyzing the results for the creep experiment, we can represent the second stage of the creep curve as a straight line under all applied stresses with high accuracy, i.e., the deformation of asphalt concrete under constant stress occurs at a constant rate $\dot{\varepsilon}_{2}$ (Figure 7). Figure 8 shows that the strain rate depends on the stress, and its dependence is satisfactorily described by a power function. It should be emphasized that stress impacts greatly on strain rate: the increase of the stress by one order causes the increase of strain rate approximately by four orders.

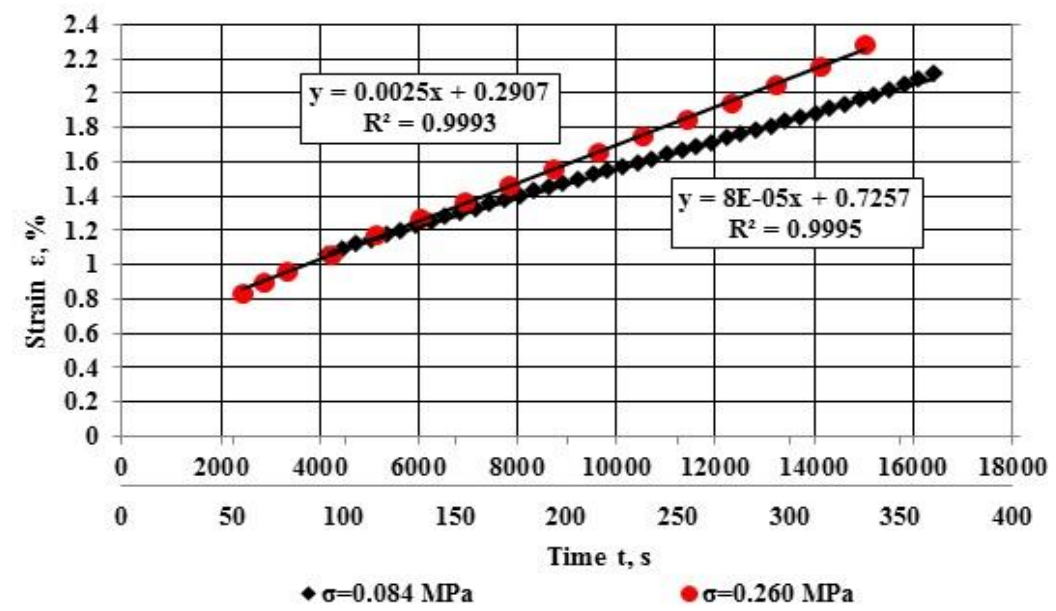

Figure 7. Stage II of asphalt concrete creep curves under stress between 0.084 and $0.260 \mathrm{MPa}$.

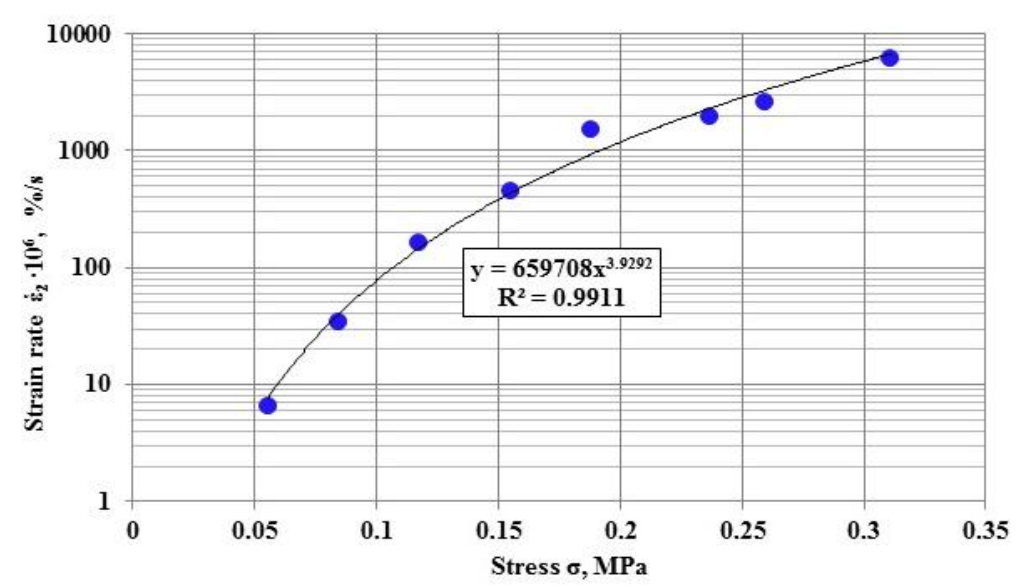

Figure 8. Dependence of steady-state creep rate on stress.

It is very important to know when steady-state creep starts and finishes, and the length of duration. As Figures 9-11 show, the specific time characteristics of asphalt concrete depend on stress and are satisfactorily approximated by a power function. It was found that the stress also impacts greatly on start point, end point, and steady-state creep duration, where the increase of stress for one order increases these time characteristics for 4.3-4.5 orders. 


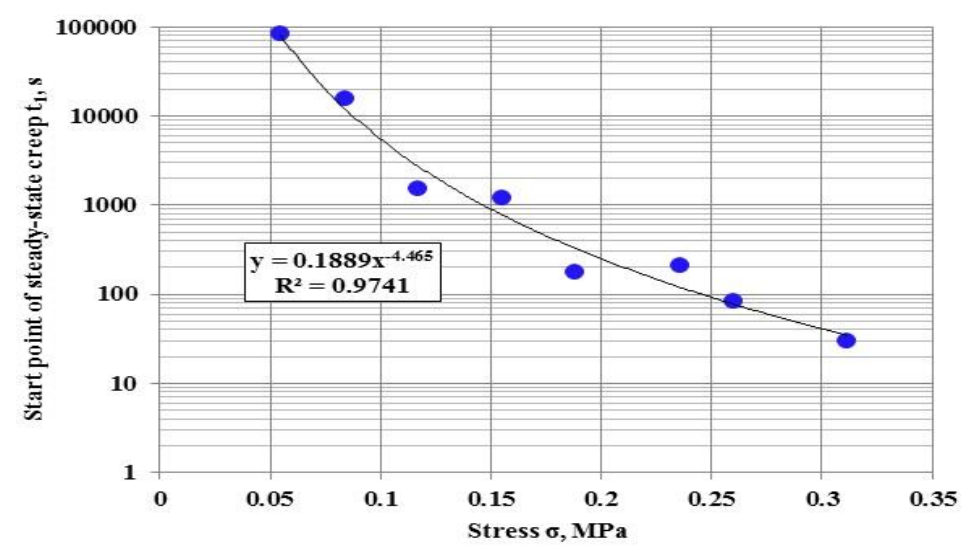

Figure 9. Dependence of start point for the stage of steady-state creep on stress.

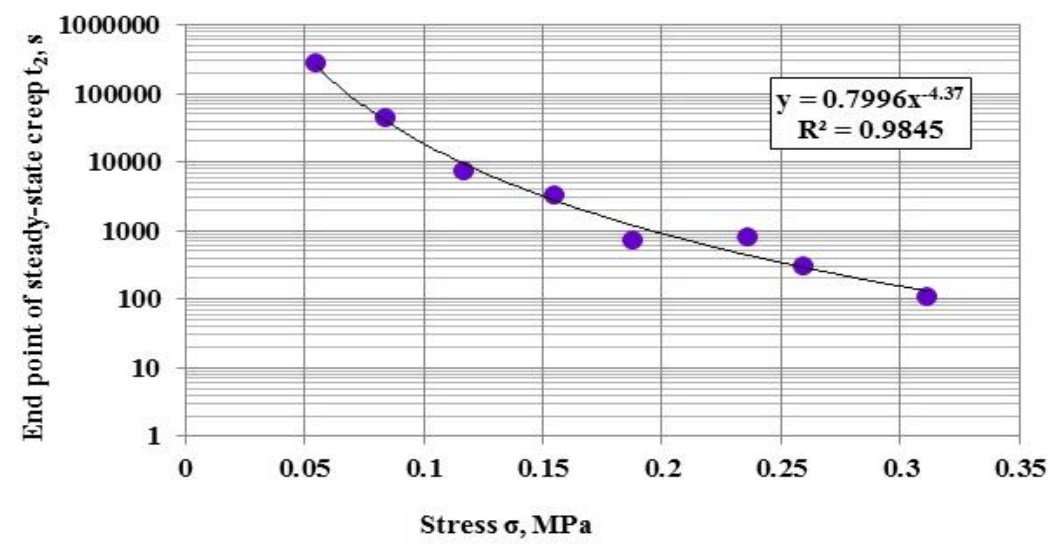

Figure 10. Dependence of end point for the stage of steady-state creep on stress.

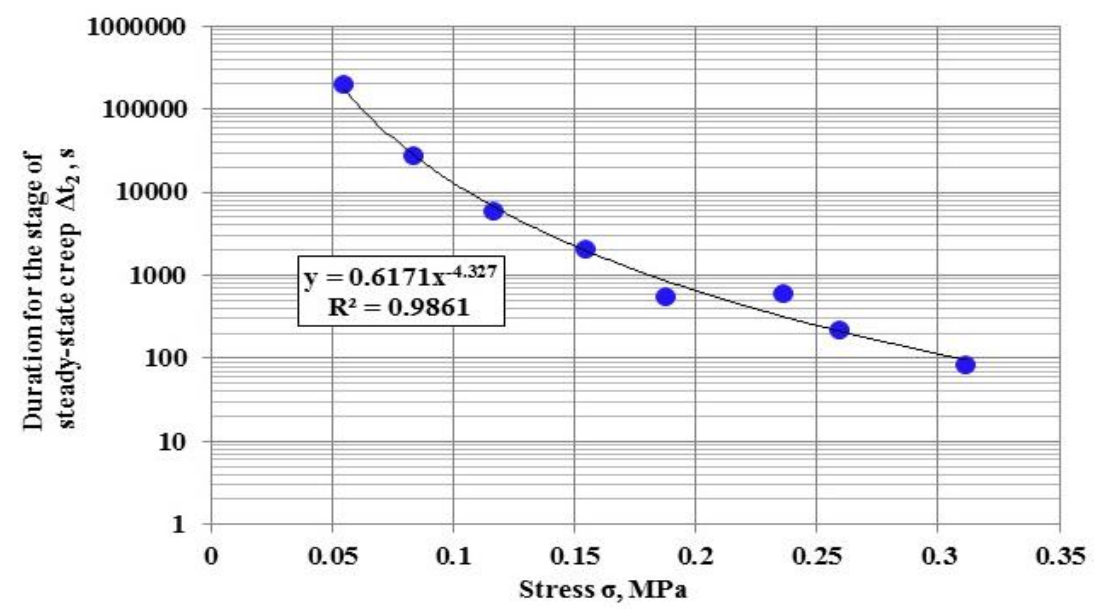

Figure 11. Dependence of duration for the stage of steady-state creep.

To show the full strain reached by the start of stage II of the creep curve through $\varepsilon_{1}$, then the strain of creep for this stage at any time $t$, is calculated as:

$$
\varepsilon_{2}(t)=\varepsilon_{1}+\dot{\varepsilon}_{2} \cdot t, \quad\left(t_{1}<t \leq t_{2}\right),
$$

where $\varepsilon_{2}(t)$ is strain of creep at time moment $t, \% ; \varepsilon_{1}$ is the strain at the start of stage II for creep curve, $\%$; $\dot{\varepsilon}_{2}$ is the steady-state creep rate, $\% / \mathrm{s}$; $t$ is time, s. 
As a result of processing by the least square method, the following dependence was obtained between the steady-state creep rate of asphalt concrete and stress (Figure 8):

$$
\dot{\varepsilon}_{2}=0,6597 \cdot \sigma^{3,9292},
$$

where $\sigma$ is stress, MPa.

Having substituted the dependence in Equation (2) into Equation (1), we have:

$$
\varepsilon_{2}(t)=\varepsilon_{1}+0,6597 \cdot \sigma^{3,9292} \cdot t, \quad\left(t_{1}<t \leq t_{2}\right) .
$$

As mentioned above, the dependences of start point $t_{1}$ and end point $t_{2}$ of steady-state creep on stress are approximated by power functions, and in particular by the following ones (Figures 9 and 10):

$$
\begin{aligned}
& t_{1}=0,1889 \cdot \sigma^{-4,465}, \\
& t_{2}=0,7996 \cdot \sigma^{-4,370} .
\end{aligned}
$$

The strain $\varepsilon_{1}$ can be calculated by the methods described in [14]. Equations (3)-(5) allow the determination of the creep strain of asphalt concrete for the stage of steady-state creep (stage II) at the time moment $t\left(t_{1}<t \leq t_{2}\right)$.

Similar to Newton's law for ideal viscous liquid, in our case for each creep curve, we can write [24]:

$$
\sigma=\eta \times \dot{\varepsilon}_{2}
$$

where $\sigma$ is stress; $\dot{\varepsilon}_{2}$ is steady-state creep (flow) rate; $\eta$ is viscosity of steady-state flow.

Additionally, for all considered stress variation limit, we can write the Equation (6) in the following form:

$$
\sigma=\eta(\sigma) \cdot \dot{\varepsilon}_{2}(\sigma)
$$

From Equation (7), we obtain viscosity:

$$
\eta(\sigma)=\frac{\sigma}{\dot{\varepsilon}_{2}(\sigma)} .
$$

The dependence of viscosity of asphalt concrete on stress, constructed under the Equation (8) with the use of experimental results, is shown in Figure 12, which is satisfactorily approximated by a power function. The stress impacts greatly on the viscosity of asphalt concrete, the increase of stress by one order reduces the viscosity by three orders.

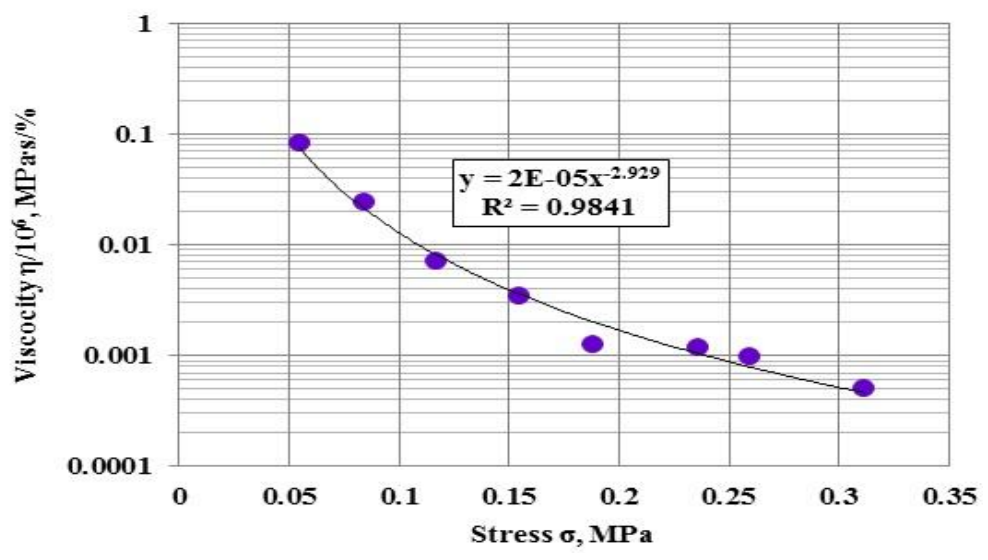

Figure 12. Dependence of viscosity for asphalt concrete on stress. 


\subsection{Defining Relations for Steady-State Creep of Asphalt Concrete at Complex Stressed Condition}

In the reality of pavement structure, the points of asphalt concrete pavement during the loading impact of vehicle wheels are in a complex stressed and strained condition [3,25]. Experimental tests for determining the mechanical characteristics of asphalt concrete, as a rule, are carried out under simple loading and strain schemes (uniaxial tension, uniaxial compression, three-point bending, four-point bending) [2]. Therefore, the integration of these experimental results, which are carried out under simple loading and strain schemes for cases of complex stress and strained condition, is of significant importance for use in practice [24].

By assuming that $(x, y, z)$ is a Cartesian coordinate system, the stressed condition in point of asphalt concrete pavement is described by stress tensor [26]:

$$
\left(\begin{array}{ccc}
\sigma_{x x} & \sigma_{x y} & \sigma_{x z} \\
\sigma_{y x} & \sigma_{y y} & \sigma_{y z} \\
\sigma_{z x} & \sigma_{z y} & \sigma_{z z}
\end{array}\right)=\left(\begin{array}{ccc}
\sigma_{0} & 0 & 0 \\
0 & \sigma_{0} & 0 \\
0 & 0 & \sigma_{0}
\end{array}\right)+\left(\begin{array}{ccc}
\sigma_{x x}-\sigma_{0} & \sigma_{x y} & \sigma_{x z} \\
\sigma_{y x} & \sigma_{y y}-\sigma_{0} & \sigma_{y z} \\
\sigma_{z x} & \sigma_{z y} & \sigma_{z z}-\sigma_{0}
\end{array}\right)
$$

where $\left(\begin{array}{ccc}\sigma_{x x}-\sigma_{0} & \sigma_{x y} & \sigma_{x z} \\ \sigma_{y x} & \sigma_{y y}-\sigma_{0} & \sigma_{y z} \\ \sigma_{z x} & \sigma_{z y} & \sigma_{z z}-\sigma_{0}\end{array}\right)$ is the deviator of stress; and $\sigma_{0}=\frac{1}{3}\left(\sigma_{x x}+\sigma_{y y}+\sigma_{z z}\right)$ is the mean stress.

Strained condition in the point is determined by strain rate tensor:

$$
\left(\begin{array}{lll}
\dot{\varepsilon}_{x x} & \dot{\varepsilon}_{x y} & \dot{\varepsilon}_{x z} \\
\dot{\varepsilon}_{y x} & \dot{\varepsilon}_{y y} & \dot{\varepsilon}_{y z} \\
\dot{\varepsilon}_{z x} & \dot{\varepsilon}_{z y} & \dot{\varepsilon}_{z z}
\end{array}\right)=\left(\begin{array}{ccc}
\dot{\varepsilon}_{0} & 0 & 0 \\
0 & \dot{\varepsilon}_{0} & 0 \\
0 & 0 & \dot{\varepsilon}_{0}
\end{array}\right)+\left(\begin{array}{ccc}
\dot{\varepsilon}_{x x}-\dot{\varepsilon}_{0} & \dot{\varepsilon}_{x y} & \dot{\varepsilon}_{x z} \\
\dot{\varepsilon}_{y x} & \dot{\varepsilon}_{y y}-\dot{\varepsilon}_{0} & \dot{\varepsilon}_{y z} \\
\dot{\varepsilon}_{z x} & \dot{\varepsilon}_{z y} & \dot{\varepsilon}_{z z}-\dot{\varepsilon}_{0}
\end{array}\right)
$$

where $\left(\begin{array}{ccc}\dot{\varepsilon}_{x x}-\dot{\varepsilon}_{0} & \dot{\varepsilon}_{x y} & \dot{\varepsilon}_{x z} \\ \dot{\varepsilon}_{y x} & \dot{\varepsilon}_{y y}-\dot{\varepsilon}_{0} & \dot{\varepsilon}_{y z} \\ \dot{\varepsilon}_{z x} & \dot{\varepsilon}_{z y} & \dot{\varepsilon}_{z z}-\dot{\varepsilon}_{0}\end{array}\right)$ is the deviator of strain rates; and $\dot{\varepsilon}_{0}=\frac{1}{3}\left(\dot{\varepsilon}_{x x}+\dot{\varepsilon}_{y y}+\dot{\varepsilon}_{z z}\right)$ is the mean strain.

As seen in Figure 13, the strain of asphalt concrete at the start $\varepsilon_{1}$ and final $\varepsilon_{2}$ of the steady-state creep depends on the stress and at a minimum stress of $0.055 \mathrm{MPa}$, does not exceed $1.2 \%$ and $1.9 \%$ respectively, i.e., they are very small.

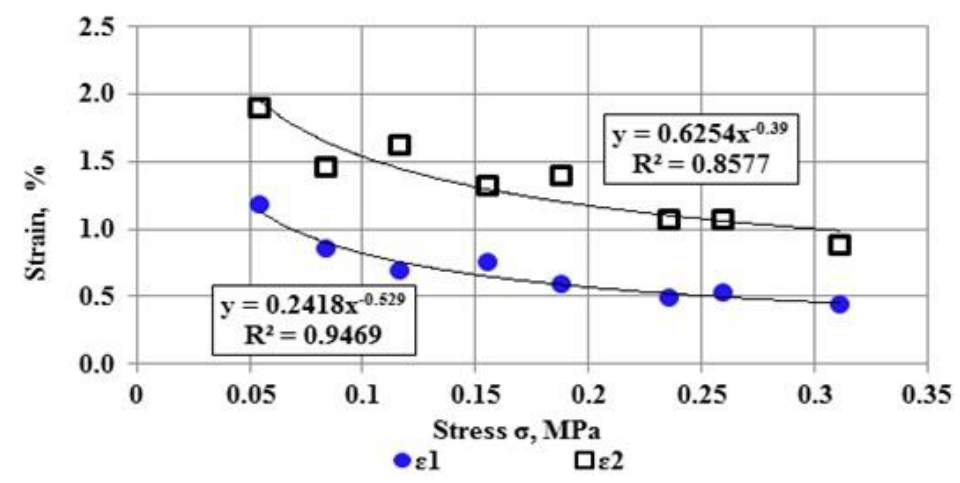

Figure 13. Dependence of strains $\varepsilon_{1}$ and $\varepsilon_{2}$ on stress.

To describe the steady-state creep of asphalt concrete, we assumed the following three hypotheses:

(1) Material is uncompressible, i.e., the incompressibility condition is true [24]:

$$
\dot{\varepsilon}_{x x}+\dot{\varepsilon}_{y y}+\dot{\varepsilon}_{z z}=0
$$


(2) The deviator of stresses is proportional to deviator of strain rates [24]:

$$
\begin{array}{ll}
\sigma_{x x}-\sigma_{0}=\psi \dot{\varepsilon}_{x x}, & \sigma_{x y}=\psi \dot{\varepsilon}_{x y}, \\
\sigma_{y y}-\sigma_{0}=\psi \dot{\varepsilon}_{y y}, & \sigma_{y z}=\psi \dot{\varepsilon}_{y z}, \\
\sigma_{z z}-\sigma_{0}=\psi \dot{\varepsilon}_{z z}, & \sigma_{z x}=\psi \dot{\varepsilon}_{z x},
\end{array}
$$

where $\psi$ is the parameter of proportionality depending on stress and strain rates.

Stress intensity:

$$
\sigma_{i}=\frac{1}{\sqrt{2}} \sqrt{\left(\sigma_{x x}-\sigma_{y y}\right)^{2}+\left(\sigma_{y y}-\sigma_{z z}\right)^{2}+\left(\sigma_{z z}-\sigma_{x x}\right)^{2}+6\left(\sigma_{x y}{ }^{2}+\sigma_{y z}{ }^{2}+\sigma_{z x}{ }^{2}\right)} .
$$

Strain rate intensity:

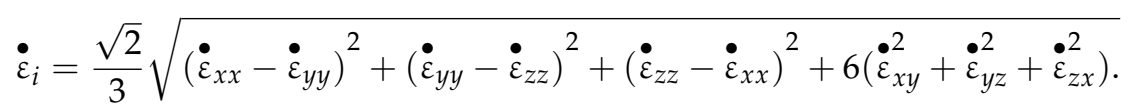

Having substituted the Equation (12) into Equation (13), we have

$$
\sigma_{i}=\frac{1}{\sqrt{2}} \sqrt{\psi^{2}\left[\left(\dot{\varepsilon}_{x x}-\dot{\varepsilon}_{y y}\right)^{2}+\left(\dot{\varepsilon}_{y y}-\dot{\varepsilon}_{z z}\right)^{2}+\left(\dot{\varepsilon}_{z z}-\dot{\varepsilon}_{x x}\right)^{2}+6\left(\dot{\varepsilon}_{x y}^{2}+\dot{\varepsilon}_{y z}^{2}+\dot{\varepsilon}_{z x}^{2}\right)\right]} .
$$

Comparison of Equation (15) with Equation (14) shows that

$$
\sigma_{i}=\frac{3}{2} \psi \dot{\varepsilon}_{i}
$$

From Equation (16), we obtained

$$
\psi=\frac{2}{3} \frac{\sigma_{i}}{\dot{\varepsilon}_{i}}
$$

Then, we write Equation (12) again considering Equation (17):

$$
\begin{array}{lll}
\sigma_{x x}-\sigma_{0}=\frac{2}{3} \frac{\sigma_{i}}{\dot{\varepsilon}_{i}} \dot{\varepsilon}_{x x}, & \sigma_{x y}=\frac{2}{3} \frac{\sigma_{i}}{\dot{\varepsilon}_{i}} \dot{\varepsilon}_{x y}, \\
\sigma_{y y}-\sigma_{0}=\frac{2}{3} \frac{\sigma_{i}}{\dot{\varepsilon}_{i}} \dot{\varepsilon}_{y y}, & \sigma_{y z}=\frac{2}{3} \frac{\sigma_{i}}{\dot{\varepsilon}_{i}} \dot{\varepsilon}_{y z} \\
\sigma_{z z}-\sigma_{0}=\frac{2}{3} \frac{\sigma_{i}}{\dot{\varepsilon}_{i}} \dot{\varepsilon}_{z z}, & \sigma_{z x}=\frac{2}{3} \frac{\sigma_{i}}{\dot{\varepsilon}_{i}} \dot{\varepsilon}_{z x} .
\end{array}
$$

(3) There is a functional dependence between stress intensity and strain rate intensity, which does not depend on the type of stressed condition:

$$
\dot{\varepsilon}_{i}=f\left(\sigma_{i}\right) .
$$

For uniaxial tension $\sigma_{x x}>0, \sigma_{y y}=\sigma_{z z}=\sigma_{x y}=\sigma_{y z}=\sigma_{z x}=0$. Therefore, from Equation (13), we have

$$
\sigma_{i}=\sigma_{x x}
$$

Considering the condition of incompressibility for the material from Equation (11) for uniaxial tension is also true, $\dot{\varepsilon}_{x x}>0, \dot{\boldsymbol{\varepsilon}}_{x y}=\dot{\boldsymbol{\varepsilon}}_{y z}=\dot{\boldsymbol{\bullet}}_{z x}=0, \dot{\bullet}_{y y}=\dot{\boldsymbol{\varepsilon}}_{z z}=-\frac{1}{2} \dot{\boldsymbol{\varepsilon}}_{x x}$.

Then, from Equation (14), we have

$$
\dot{\varepsilon}_{i}=\dot{\varepsilon}_{x x}
$$


Taking into account Equations (19)-(21) for the considered asphalt concrete, the relation between strain rate intensity and stress intensity will have the following form:

$$
\dot{\varepsilon}_{i}=0.6597 \cdot \sigma_{i}{ }^{3.9292},
$$

where $\dot{\varepsilon}_{i}$ is strain rate intensity, \%/s; $\sigma_{i}$ is stress intensity, MPa.

Comparing Equations (19) and (22), we have

$$
f\left(\sigma_{i}\right)=0.6597 \cdot \sigma^{3.9292} .
$$

The previous paper in Reference [22] showed that asphalt concrete is deformed as a plastic material at $20^{\circ} \mathrm{C}$ during cyclic loading under scheme "loading-deforming under constant load-rest". Thus, keeping the applied stress equal to $0.138 \mathrm{MPa}$ constant for $120 \mathrm{~s}$ and keeping the asphalt concrete sample without load for the following $300 \mathrm{~s}$ in each cycle showed that even after four to five cycles the elastic (recovered) strain was only $5 \%-6 \%$ (Figure 14), i.e., asphalt concrete was deformed plastically.

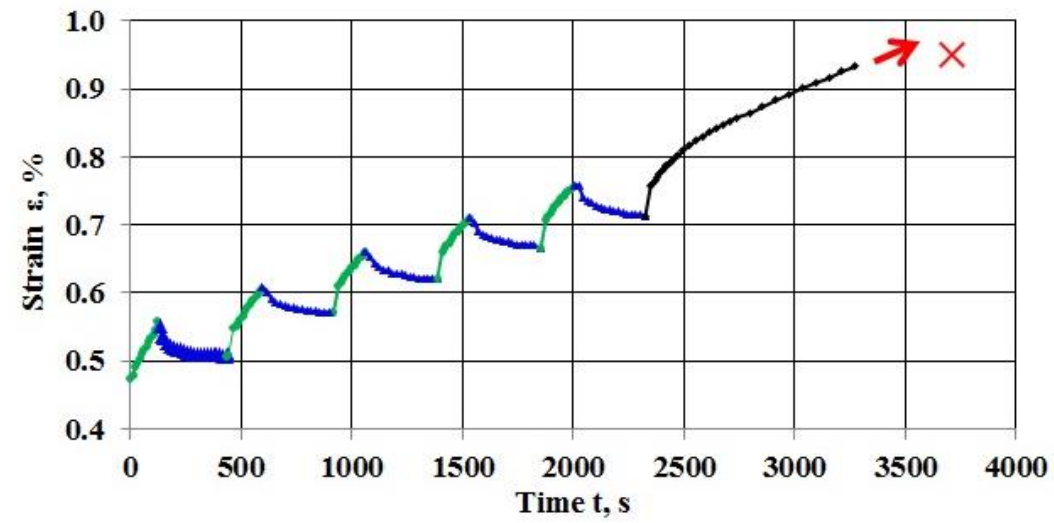

Figure 14. Curve of asphalt concrete strain during cyclic loading, green line: creep under load; blue line: recovery of strain after unloading; red cross: failure.

The above data emphasized the importance of defining relations for the steady-state creep of asphalt concrete as seen in Equations (18) and (22); and should also be considered as defining relations for steady-state plastic flow. By using them we can set the problems and solve them for the modeling of rutting in asphalt concrete layers of highways (Figure 15).

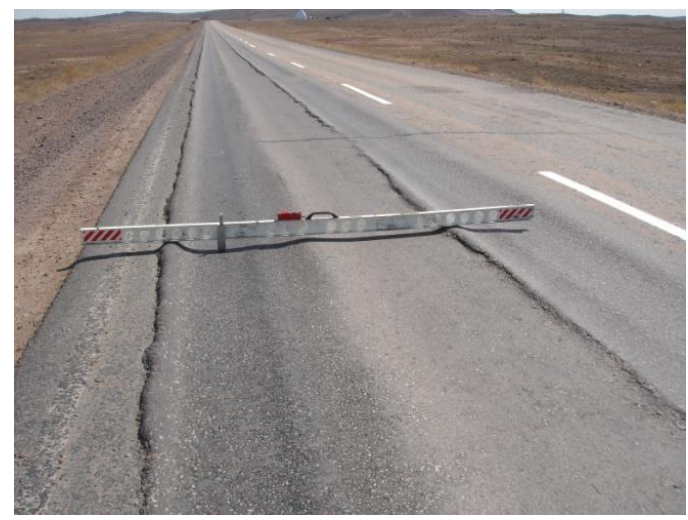

Figure 15. Plastic strains (the depth of the rut is more than $60 \mathrm{~mm}$ ) in asphalt concrete layers of the highway "Ekaterinburg-Almaty" (km 1903.1-Karaganda Region, Kazakhstan). 


\section{Conclusions}

The results of the experimental investigation into fine-grained asphalt concrete at static loading at a temperature of $20 \pm 2{ }^{\circ} \mathrm{C}$ and at stress between 0.055 and $0.311 \mathrm{MPa}$ showed the following:

- $\quad$ For creep curve stage II, the asphalt concrete deformation occurred at a constant rate. The strain rate for this stage is dependent on the stress, and this dependence is satisfactorily described by a power function. The stress has a great influence on the strain rate where the increase of stress by one order increases the strain rate approximately by four orders;

- The dependences were constructed for the start point, end point, and the duration of the stage of steady-state creep on the stress. The stress also impacts greatly on the specified time characteristics, where the increase of stress by one order increases these characteristics for $4.3-4.5$ orders;

- The values of viscosity for asphalt concrete were determined at various stresses. The dependence was defined for viscosity on the stress and can also be satisfactorily described by a power function. In particular, the increase of stress by one order reduces the viscosity by three orders;

- Assuming that asphalt concrete is an incompressible material, then the stress deviator is proportional to the strain rate deviator. Hence, there is a functional relationship between the stress intensity and the strain rate intensity, which does not depend on the type of stress condition. The defining relations were formulated for the steady-state creep of asphalt concrete under complex stressed conditions.

Acknowledgments: This research is supported by the Road Committee of the Ministry for Investments and Development of the Republic of Kazakhstan (Agreement No. 36 dated 21 July 2016).

Author Contributions: Alibai Iskakbayev and Bagdat Teltayev conceived and designed the experiments; Alibai Iskakbayev and Bagdat Teltayev performed the experiments; Alibai Iskakbayev, Bagdat Teltayev and Cesare Oliviero Rossi analysed the data; Alibai Iskakbayev, Bagdat Teltayev and Cesare Oliviero Rossi contributed reagents/materials/analysis tools; Alibai Iskakbayev, Bagdat Teltayev and Cesare Oliviero Rossi wrote the paper.

Conflicts of Interest: The authors declare no conflict of interest.

\section{References}

1. The Asphalt Handbook (MS-4), 7th ed.; Asphalt Institute: Lexington, MA, USA, 2008.

2. Papagiannakis, A.T.; Masad, E.A. Pavement Design and Materials; John Wiley \& Sons, Inc.: New Jersey, NJ, USA, 2008.

3. Yoder, E.J.; Witczak, M.W. Principles of Pavement Design; John Wiley \& Sons, Inc.: New Jersey, NJ, USA, 1975.

4. Cristensen, R.M. Theory of Viscoelasticity: An Introduction; Academic Press: New York, NY, USA, 1971.

5. Ferry, J.D. Viscoelastic Properties of Polymers; John Wiley \& Sons, Inc.: New York, NY, USA, 1980.

6. Tschoegl, N.W. The Phenomenological Theory of Linear Viscoelastic Behavior. An Introduction; Springer: Berlin, Germany, 1989.

7. Hopkins, I.L.; Hamming, R.W. On creep and relaxation. J. Appl. Phys. 1957, 28, 906-909. [CrossRef]

8. Taherkhani, H. Compressive creep behavior of asphalt mixtures. Eng. Procedia 2011, 10, 583-588. [CrossRef]

9. Hassan, M.M. Relationship between creep time dependent index and Paris low parameters for bituminous mixtures. J. S. Afr. Inst. Civ. Eng. 2013, 2, 8-11.

10. Soleimanbeigi, A.; Edil, T.B.; Benson, C.H. Creep response of recycled asphalt shingles. Can. Geotech. J. 2013, 51, 103-114. [CrossRef]

11. Mahan, H.M. Behavior of permanent deformation in asphalt concrete pavements under temperature variation. Al-Qadisiya J. Eng. Sci. 2013, 1, 62-73.

12. Zhou, Z.G.; Feng, L.; Yuan, X.X.; Xiong, H. Study of the creep damage properties of asphalt mixture under static load. In Proceedings of the 13th International Conference on Fracture, Beijing, China, 16-21 June 2013.

13. Jaczewski, M.; Judycki, J. Effects of deviations from thermo-rheologically simple behavior of asphalt mixtures in creep on developing of master curves of their stiffness modulus. In Proceedings of the 9th International Conference on Environmental Engineering, Vilnius, Lithuania, 22-23 May 2014. 
14. Iskakbayev, A.; Teltayev, B.; Alexandrov, S. Determination of the creep parameters of linear viscoelastic materials. J. Appl. Math. 2016, 2016, 6568347. [CrossRef]

15. Kachanov, L. Introduction to Continuum Damage Mechanics; Martinus Nijhoff Publishers: Dordrecht, The Netherlands, 1986.

16. Rabotnov, Y.N. Introduction to Fracture Mechanics; Nauka: Moscow, Russia, 1987.

17. Bitumens and Bitumen Binders. Oil Road Viscous Bitumens (ST RK 1373); Technical Specifications: Astana, Kazakhstan, 2013.

18. Performance Graded Asphalt Binder Specification and Testing (Superpave Series No. 1); Asphalt Institute: Lexington, MA, USA, 2003.

19. Hot Mix Asphalt for Roads and Airfields (ST RK 1225); Technical Specifications: Astana, Kazakhstan, 2013.

20. Crushed Stone and Gravel of Dense Rock for Construction Works (ST RK 1284); Technical Specifications: Astana, Kazakhstan, 2004.

21. Bituminous Mixtures. Test Methods for Hot Mix Asphalt. Part 33: Specimen Prepared by Roller Compactor (EN 12697-33); European Committee for Standardization: Brussels, Belgium, 2003.

22. Iskakbayev, A.; Teltayev, B.; Andriadi, F.; Estayev, K.; Suppes, E.; Iskakbayeva, A. Experimental research of creep, recovery and fracture processes of asphalt concrete under tension. In Proceedings of the 24th International Congress on Theoretical and Applied Mechanics, Montreal, QC, Canada, 21-26 August 2016.

23. Teltayev, B.B.; Iskakbayev, A.I.; Rossi, C.O. Regularities of Creep and Long-Term Strength of Hot Asphalt Concrete under Tensile. In Proceedings of the 4th Chinese-European Workshop "Functional Pavement Design", Delft, The Netherlands, 29 June-1 July 2016.

24. Nadai, A. Theory of Flow and Fracture of Solids; MeGraw-Hill: New York, NY, USA, 1963.

25. Huang, Y.H. Pavement Analysis and Design, 2nd ed.; Pearson Education, Inc.: Upper Saddle River, NJ, USA, 2004.

26. Talreja, R.; Sing, C.V. Damage and Failure of Composite Materials; Cambridge University Press: Cambridge, UK, 2012.

(C) 2017 by the authors; licensee MDPI, Basel, Switzerland. This article is an open access article distributed under the terms and conditions of the Creative Commons Attribution (CC BY) license (http:/ / creativecommons.org/licenses/by/4.0/). 